Ministry of Defense

Military Technical College

Kobry Elkobbah, Cairo, Egypt

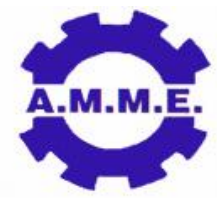

AMME-14 $14^{\text {th }}$ International Conference on Applied Mechanics and Mechanical Engineering

May, 25 - 27, 2010

\title{
BE-3
}

\section{Metallurgy of Cement-less T.H.R}

Maj. Gen. Dr /Raoof El-Abbasy

Commandant of Helmia Orthopedic Army Hospital

\begin{abstract}
:
Cementless THA represents the biological fixation of hip implants via micro-mechanical interlock in the host bone. It is mainly indicated in young active patients with high demands and in revision THA to avoid inserting a revision stem in dead materials. Knowledge of basic metallurgic terms is essentially in cementless in THA. The stress strain diagram showing elastic and plastic range of deformation is essentially for good understanding of cementless THR. Also in comparison of mechanical properties of materials used in THA including modulus of elasticity and fatigue strength is an essential item in choosing the best material for implants used in cementless THA.
\end{abstract}

